\title{
Cross-sectional Study of Respiratory Symptoms and Pulmonary Functions in Rayon Textile Workers with Special Reference to $\mathrm{H}_{2} \mathrm{~S}$ Exposure
}

\author{
Toshiaki HIGASHI*, Toshio TOYAMA*, Haruhiko SAKURAI*, \\ Masahiro NAKAZA*, Kazuyuki OMAE*, Toshio NAKADATE** \\ and Naohito YAMAGUCHI* \\ * Department of Preventive Medicine and Public Health, \\ School of Medicine, Keio University, \\ 35 Shinano-machi, Shinjuku-ku, Tokyo 160, Japan \\ ** National Institute of Industrial Health, \\ 21-1, Nagao 6-chome, Tama-ku, Kawasaki 214, Japan
}

(Received August 1, 1983 and in revised form September 12, 1983)

\begin{abstract}
A cross-sectional study on pulmonary functions and respiratory symptoms was undertaken in Japanese male workers in 18 viscose rayon plants to detect pulmonay effects associated with viscose exposure, especially to $\mathrm{H}_{2} \mathrm{~S}$. Measurement of the occupational exposure level $(\mathrm{OEL})$ of $\mathrm{H}_{2} \mathrm{~S}$ by personal passive diffusion dosimetry, and the forced expiratory flow-volume test before and after an eighthour shift on the same workday was undertaken in 30 matched pairs of exposed and non-exposed workers. The $\mathrm{OEL}$ of $\mathrm{H}_{2} \mathrm{~S}$ was 0.3 to $7.8 \mathrm{ppm}, 3 \mathrm{ppm}$ on the average, for the viscose exposed workers and less than $0.1 \mathrm{ppm}$ for the referents. No significant difference in the eight-hour pulmonary function changes between the pairs was observed, and no significant correlation between the individual pulmonary function changes and individual $\mathrm{OEL}$ of $\mathrm{H}_{2} \mathrm{~S}$ was obtained. Indices of the forced expiratory flow-volume test for 324 workers appeared to be better in exposed non-smokers than in non-exposed non-smokers. The prevalence rates of respiratory symptoms in 2379 exposed and 2968 referent workers using a modified self-administered BMRC questionnaire showed significant associations with smoking habits, but not with rayon work-history. No evidence of any appreciable effect of viscose exposure on pulmonary functions and symptoms was revealed in the Japanese rayon plant workers.
\end{abstract}

Key words: Hydrogen sulfide - Flow-volume curve-Prevalence of respiratory symptoms-Viscose rayon-Matched pair-Occupational exposure level

\section{INTRODUCTION}

The principal health hazards in viscose rayon fiber plants have been chronic carbon disulfide $\left(\mathrm{CS}_{2}\right)$ intoxication (Kubota; Hernberg et al.; Hanninen; Fajen 
et $a l.)^{1-4)}$ and the acute irritative effects cf hydrogen sulfide $\left(\mathrm{H}_{2} \mathrm{~S}\right)$ on the conjunctiva (Nyman; Milby), ${ }^{5,6)}$ while pulmonary effects due to these chemicals have been a minor occupational health problem. Acute pulmonary effects of $\mathrm{H}_{2} \mathrm{~S}$ exposure at high concentrations, i.e., more than $500 \mathrm{ppm}$, were reported to be death by paralysis of the respiratory center (Simson et al.; Smith et al. ) $^{7,8)}$ or hemorrhagic pulmonary edema in near-fatal cases (Kamper; Burnett et al.)..$^{9,10)}$ These conditions resulted from accidental exposure to high concentrations of $\mathrm{H}_{2} \mathrm{~S}$. However, there have been few reports on the acute subclinical pulmonary effects of $\mathrm{H}_{2} \mathrm{~S}$ exposure at low concentration levels, and the long-term effects of $\mathrm{H}_{2} \mathrm{~S}$ have not been well documented. The Occupational Safety and Health Administration of the United States has recommended routine periodical pulmonary examinations for $\mathrm{H}_{2} \mathrm{~S}$ exposed workers (NIOSH/OSHA). ${ }^{11)}$ In Japan, the general public living near viscose rayon plants has frequently expressed concern about possible health hazards associated only with the odor or corrosive nature of $\mathrm{H}_{2} \mathrm{~S}$.

We planned a short-term one workday study and a cross-sectional prevalence study to ascertain whether exposure to viscose vapors, especially $\mathrm{H}_{2} \mathrm{~S}$, would have any acute single workday or long-term effect on pulmonary functions and respiratory symptoms in viscose rayon workers who had been expcsed steadily for some years in the same work envircnment. The cne-workday study was designed to detect the one-day immediate effects of $\mathrm{H}_{2} \mathrm{~S}$ xposure on pulmonary functions with reference to the personal index of exposure. In the cross-sectional study, the pulmonary function indices of the forced expiratory flow-volume test and the prevalance rates of respiratory symptoms assessed by a standardized questionnaire were used to determine the effects of long-term exposure as compared to nonexposed workers in the same plants. The objective cf the study was to assess reasonable estimations of the effects of occupational exposure by combining the two sets of studies.

\section{SubJECTS AND Methods}

\section{One-workday study on diurnal occupational exposure}

In October 1980,30 male $\mathrm{H}_{2} \mathrm{~S}$-exposed workers who engaged in spinning, cutting or refinery work were selected from three viscose rayon fiber plants. From each of the three plants, the same number of non-exposed workers matched to each of the exposed workers as to smoking habits, age and height was selected. Maximum deviations of the matched factors within the pairs were five cigarettes per day, three years in age and $4 \mathrm{~cm}$ in height. None of the subjects had a history of severe respiratory disorders due to any cause or acute respiratory distress resulting from acute $\mathrm{H}_{2} \mathrm{~S}$ poisoning.

The occupational exposure level (OEL) of $\mathrm{H}_{2} \mathrm{~S}$ exposure was measured by a passive diffusion dosimeter developed by the authors (Nakaza et al.). ${ }^{12)}$ The dosimeter is a small badge-type polyethylene tube containing a sheet of filter paper 
impregnated with lead acetate solution. Each exposed and reference worker wore a sampler on his lapel for 6.5 actual work-hours during the eight-hour shift. The environmental concentrations of $\mathrm{H}_{2} \mathrm{~S}$ and $\mathrm{CS}_{2}$ in the working areas were measured at representative points in the workplace by the methylene blue method (APHA) ${ }^{13)}$ and the diethylamine copper method (McKee), ${ }^{14)}$ respectively. During the survey in three plants, the geometric mean concentration of $\mathrm{H}_{2} \mathrm{~S}$ in the room air was $1.06 \mathrm{ppm}$ (geometric standard deviation, 1.82), and that of $\mathrm{CS}_{2}$ was $2.90 \mathrm{ppm}$ (g.s.d., 2.62). The mean concentrations for all 18 plants are discussed elsewhere in this text.

The forced expiratory flow-volume curves were recorded as the indices of pulmonary ventilatory capacities and of airway obstruction using an electronic spirometric instrument (Autospiroanalyzer ASC-1000, Asahi Medical). The flowvclume curves with three acceptable forced expiratory maneuvers before and after work were obtained in each subject by a chest physician, who was blinded to information as to the worker's $\mathrm{H}_{2} \mathrm{~S}$ exposure. The curve with the maximal sum of FVC and $\mathrm{FEV}_{1.0}$ (Sorensen et al.) ${ }^{15)}$ was used for analysis, and the following indices were printed out: forced vital capacity (FVC), forced expiratory volume in one second $\left(\mathrm{FEV}_{1.0}\right)$, peak expiratory flow rate (PEFR), maximum expiratory flow rate at $75 \%\left(\mathrm{MEF}_{75}\right)$, at $50 \%\left(\mathrm{MEF}_{50}\right)$ and at $25 \%\left(\mathrm{MEF}_{25}\right)$ of the FVC, percentage rate of $\mathrm{FEV}_{1.0}$ to $\mathrm{FVC}\left(\mathrm{FEV}_{1.0} \%\right)$, and ratio of $\mathrm{MEF}_{50}$ to $\mathrm{MEF}_{25}\left(\mathrm{MEF}_{50} / \mathrm{MEF}_{25}\right)$. The flow-volume tests were performed twice on the same day. The initial measurements were done in the morning (6 to 7 a.m.) a few minutes prior to starting a routine day shift and the second at the end of the day ( 2 to 3 p.m.). Smokers were asked to refrain from smoking for at least one hour before the measurements. The measurement of $\mathrm{H}_{2} \mathrm{~S}$ exposure (OEL) and the pulmonary function tests were conducted on the same workers on the same day.

\section{Cross-sectional prevalance study on exposure-referent respiratory symptoms}

In the three representative viscose rayon plants of a total of 18 throughout Japan, the flow-volume test was performed utilizing the same procedure as described above on 324 subjects, 115 exposed workers and 209 referents, in which the 30 pairs of exposed and non-exposed workers appearing in the former study were included. Each subject underwent the pulmonary function measurement once a day between 10 a.m. and 2 p.m., and, for the 30 pairs, the data of the second measurement (end of work) were used for analysis. Prediction equations from the data of non-exposed healthy workers in other industries in Japan (Sakurai et al. $)^{16)}$ were used to estimate the expected pulmonary function values.

The prevalence rates of respiratory symptoms were obtained by utilizing a self-administered standard questionnaire in male workers in 18 viscose rayon fiber plants with the assistance of the Japan Chemical Fiber and Textile Association. The questionnaire, which was a slightly revised Japanese version of the British 
Medical Research Council's short questionnaire on respiratory symptoms with enforced occupational history, was distributed to 7200 workers through plant physicians or plant health supervisors of the individual plants and returned directly to the authors. The number of replies was 6670 , for a response rate of $93 \%$. Subjects with experience of work in a dusty job or apparent pulmonary diseases before employment as well as incomplete answers to the questionnaires were omitted from the analysis. Thus, 5347 questionnaires from 2379 exposed workers and 2968 referents were usable for analysis. Logistic regression analysis (Cox; Lemeshow et al. $)^{17,18)}$ was used for the evaluation of the associations between the respiratory symptoms and several related variables. To compare the results of the self-administered questionnaire with the interview method, 62 workers in the three plants were directly interviewed by the investigators using the same questionnaire about one mouth after the self-administered inquiry.

\section{RESUlts}

\section{One-workday study}

Table 1 shows the area distribution of the plants surveyed and the age, height, weight and cigarette consumption of the $\mathrm{H}_{2} \mathrm{~S}$ exposed workers and the matched referents. Because matching for cigarette smoking habits was undertaken on the basis of current smoking patterns, three former smokers who had quit more than three years before were categorized as non-smokers in the reference group. Between the 30 exposed workers and their matched referents, no significant difference in the prevalence rates of individual respiratory symptoms was noted. As shown in Table 2, no significant difference within the matched pairs was seen

Table 1. Area distribution, physical characteristics, smoking habits and duration of exposure of 30 matched pair in three plants

\begin{tabular}{lcc}
\hline & $\begin{array}{c}\mathrm{H}_{2} \text { S-exposed workers } \\
(\mathrm{n}=30)\end{array}$ & $\begin{array}{c}\text { Reference workers } \\
(\mathrm{n}=30)\end{array}$ \\
\hline $\begin{array}{l}\text { Area distribution } \\
\text { North }\end{array}$ & 7 & 7 \\
$\quad$ Inland-sea & 11 & 11 \\
$\quad$ South & 12 & 12 \\
Age (year), mean \pm s.d. & $39.0 \pm 9.5$ & $40.0 \pm 8.3$ \\
Height (cm), mean \pm s.d. & $166.3 \pm 6.5$ & $165.6 \pm 3.8$ \\
Weight (kg), mean \pm s.d. & $63.2 \pm 7.8$ & $62.3 \pm 6.5$ \\
Current smoking habits & $24(80 \%)$ & $24(80 \%)$ \\
$\quad$ 14 cigarettes/day & 9 & 8 \\
15-24 cigarettes/day & 14 & 12 \\
$\quad \geqq 25$ cigarettes/day & 1 & 4 \\
Number of nonsmokers & 6 & 3 \\
Number of exsmokers & - & - \\
Duration of exposure (year), mean \pm s.d. & $12.3 \pm 7.7$ & 3 \\
\hline
\end{tabular}


Table 2. PImonary functions ${ }^{\alpha}$ in matched $\mathrm{H}_{2} \mathrm{~S}$-exposed and referent pairs (mean \pm s.d.) and significance of differonce

\begin{tabular}{lccc}
\hline & $\begin{array}{c}\mathrm{H}_{2} \text { S-exposed workers } \\
(\mathrm{n}=30)\end{array}$ & $\begin{array}{c}\text { Reference workers } \\
(\mathrm{n}=30)\end{array}$ & $\begin{array}{c}\text { Paired } \\
\text { t-test }\end{array}$ \\
\hline FVC $(l)$ & $4.25 \pm 0.73$ & $4.25 \pm 0.64$ & n.s. \\
FEEV $_{1.0}(l)$ & $3.55 \pm 0.59$ & $3.53 \pm 0.60$ & n.s. \\
FEV $_{1.0 \%}$ & $83.8 \pm 4.89$ & $83.0 \pm 5.53$ & n.s. \\
PEFR $(l / \text { sec. })_{\mathrm{MEF}_{75}(l / \mathrm{sec})}$ & $8.67 \pm 1.90$ & $8.48 \pm 1.34$ & n.s. \\
$\mathrm{MEF}_{50}(l / \mathrm{sec})$ & $8.20 \pm 1.82$ & $8.04 \pm 1.29$ & n.s. \\
$\mathrm{MEF}_{25}(l / \mathrm{sec})$ & $4.89 \pm 1.24$ & $4.81 \pm 1.29$ & n.s. \\
$\mathrm{MEF}_{50} / \mathrm{MEF}_{25}$ & $1.74 \pm 0.55$ & $1.71 \pm 0.67$ & n.s. \\
\hline
\end{tabular}

$\alpha$ : Measured in the morning before beginning the day shift.

n.s.: No significant difference between the pair.

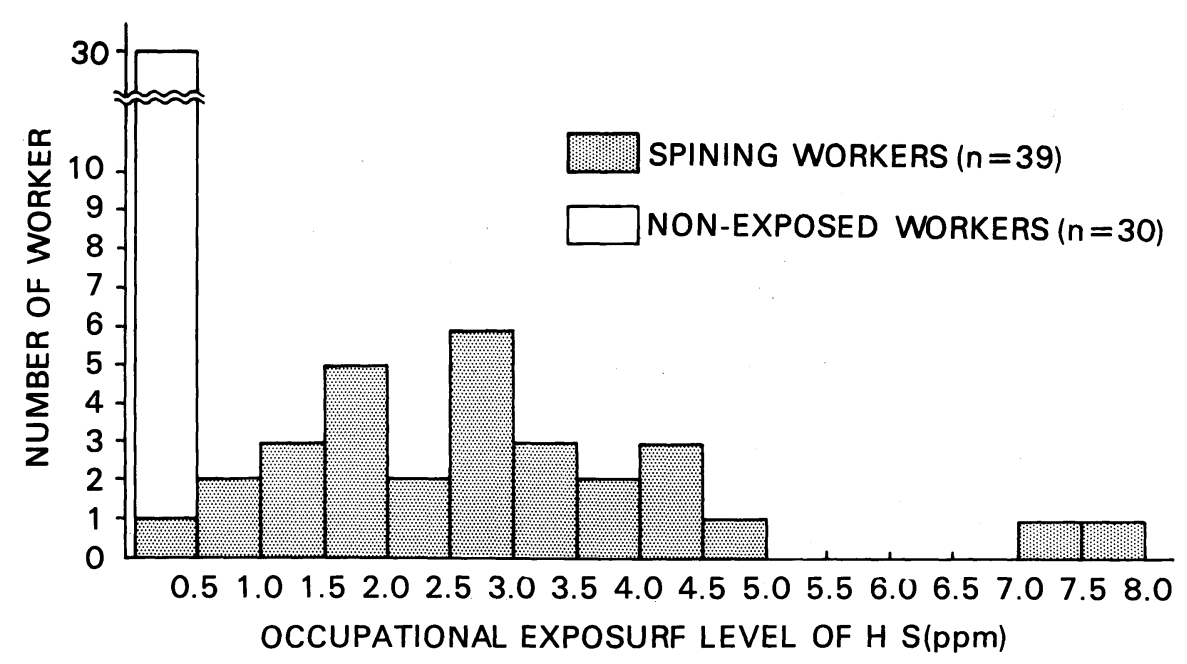

Fig. 1. Frequency distribution of personal exposure to $\mathrm{H}_{2} \mathrm{~S}$ during work hours.

in the initial pulmonary function values by the paired $t$-test, and it might be conceivable that no long-term effects of viscose exposure on pulmonary functions was indicated. Figure 1 shows the frequency distribution of occupational exposure level for $\mathrm{H}_{2} \mathrm{~S}$, as expressed by ppm, during 6.5 actual exposure hours in eight-hour shift work. The range of exposure levels (OEL) was $0.3 \mathrm{ppm}\left(0.4 \mathrm{mg} / \mathrm{m}^{3}\right)$ to $7.8 \mathrm{ppm}\left(11.0 \mathrm{mg} / \mathrm{m}^{3}\right), 3 \mathrm{ppm}$ on the average, for the viscose-exposed workers and less than $0.1 \mathrm{ppm}$ for the referents. Table 3 lists the percentage change rates of the pulmonary functions, i.e., the ratio of the second values to the initial values on the same day. No significant difference was seen by the paired $t$-test between diurnal changes in the exposed workers and those in the referents.

Table 4 shows the relationship in multiple regression between the percentage 
Table 3. Percentage change rates of pulmonary functions before and after an eight-hour day shift (mean \pm s.d.)

\begin{tabular}{lccc}
\hline & $\begin{array}{c}\mathrm{H}_{2} \text { S-exposed workers } \\
(\mathrm{n}=30)\end{array}$ & $\begin{array}{c}\text { Non-exposed workers } \\
(\mathrm{n}=30)\end{array}$ & $\begin{array}{c}\text { Paired } \\
\text { t-test }\end{array}$ \\
\hline FVC & $0.2 \pm 6.8$ & $-1.0 \pm 4.1$ & n.s. \\
FEV $_{1.0}$ & $2.8 \pm 5.8$ & $0.0 \pm 3.4$ & n.s. \\
FEV $_{1.0}$ & $3.0 \pm 4.3$ & $2.3 \pm 3.5$ & n.s. \\
PEER $_{M E F}$ & $4.7 \pm 15.4$ & $1.1 \pm 13.0$ & n.s. \\
$\mathrm{MEF}_{50}$ & $5.5 \pm 14.7$ & $4.0 \pm 15.1$ & n.s. \\
$\mathrm{MEF}_{25}$ & $8.0 \pm 14.3$ & $4.4 \pm 15.3$ & n.s. \\
$\mathrm{MEF}_{50} / \mathrm{MEF}_{25}$ & $19.7 \pm 35.4$ & $10.9 \pm 27.2$ & n.s. \\
\hline
\end{tabular}

n.s.: No significant difference qetween the pair.

Table 4. Regression coefficients, percentage change of pulmonary functions in the same day versus explanatory variables

\begin{tabular}{|c|c|c|c|c|c|c|}
\hline \multirow{2}{*}{$\begin{array}{l}\text { Percentage change of } \\
\text { pulmonary function }\end{array}$} & \multicolumn{4}{|c|}{ Variables $^{a}$} & \multirow[b]{2}{*}{$\mathrm{n}$} & \multirow[b]{2}{*}{$\mathbf{R}^{2}$} \\
\hline & Age & $\mathrm{Ht} \& \mathrm{Wt}$ & $\begin{array}{c}\text { Smoking } \\
\text { habits }\end{array}$ & $\stackrel{\mathrm{H}_{2} \mathrm{~S}}{\text { exposure }}$ & & \\
\hline FVC & .316 & -.027 & -.070 & -.081 & 30 & .206 \\
\hline $\mathrm{FEV}_{1.0}$ & .275 & -.018 & -.110 & -.053 & 30 & .245 \\
\hline $\mathrm{FEV}_{1.0} \%$ & -.026 & .009 & .047 & 0.30 & 30 & .067 \\
\hline PEFR & -.007 & .005 & -.286 & .066 & 30 & .048 \\
\hline $\mathrm{MEF}_{75}$ & -.011 & .014 & -.258 & .036 & 30 & .050 \\
\hline $\mathrm{MEF}_{50}$ & .080 & .033 & -.213 & .200 & 30 & .037 \\
\hline $\mathrm{MEF}_{25}$ & -.072 & .023 & -.205 & .071 & 30 & .042 \\
\hline $\mathrm{MEF}_{50} / \mathrm{MEF}_{25}$ & .020 & -.012 & .148 & .230 & 30 & .035 \\
\hline
\end{tabular}

$\alpha$ : Age-year; Ht \& Wt-Broca's index; Smoking hablts-daily consumption (cigarettes/day); $\mathrm{H}_{2} \mathrm{~S}$-exposure-occupational exposure level (ppm).

change of pulmonary functions and such variables as age, anthropometric characteristics, smoking habits and personal exposure concentration of $\mathrm{H}_{2} \mathrm{~S}$ (OEL) for the 30 exposed workers. The partial regression coefficients were not statistically significant in respective variables. The results indicated that diurnal occupational exposure to $\mathrm{H}_{2} \mathrm{~S}$ did not affect the pulmonary functions in the exposed workers.

\section{Cross-sectional prevalence of respiratory symptoms}

The long-term effects of viscose exposure on pulmonary functions were analyzed in 324 workers divided into four groups categorized by viscose work experience and smoking habits, as indicated in Table 5. In the same Table, the percentage ratios of the observed pulmonary functions to the predicted values computed by the prediction equations are shown. Daily cigarette consumption and duration of smoking in Groups 1 (exposed) and 3 (non-exposed) were 16.5 \pm 5.4 cigarettes and $18.2 \pm 4.8$ years and 19.1 \pm 6.1 cigarettes and 17.6 \pm 5.1 years, respectively. 
Table 5. Age and percentage-predicted pulmonary functions by viscoie exposure and smoking categories (mean \pm s.d.)

\begin{tabular}{|c|c|c|c|c|}
\hline & \multicolumn{2}{|c|}{ Viscose exposed workers } & \multicolumn{2}{|c|}{ Non-exposed workers } \\
\hline & $\begin{array}{l}\text { Smoker } \\
\text { Group } 1 \\
(n=85)\end{array}$ & $\begin{array}{c}\text { Non-smoker } \\
\text { Group } 2 \\
(n=30)\end{array}$ & $\begin{array}{l}\text { Smoker } \\
\text { Group } 3 \\
(\mathrm{n}=125)\end{array}$ & $\begin{array}{c}\text { Non-smoker } \\
\text { Group } 4 \\
(n=84)\end{array}$ \\
\hline Age (year) & $40.5 \pm 10.1$ & $41.0 \pm 9.1$ & $38.6 \pm 9.8$ & $39.5 \pm 8.8$ \\
\hline \multicolumn{5}{|l|}{ Cigarette smoking } \\
\hline Duration (year) & $15.4 \pm 5.2$ & - & $17.2 \pm 5.8$ & - \\
\hline Cigarettes per day & $17.1 \pm 4.7$ & - & $15.8 \pm 5.1$ & - \\
\hline FVC & $105.0 \pm 11.1$ & $108.3 \pm 10.2^{\mathrm{c}}$ & $103.0 \pm 12.9$ & $102.6 \pm 13.0$ \\
\hline $\mathrm{FEV}_{1.0} \%$ & $97.8 \pm 6.9$ & $100.2 \pm 6.7$ & $99.5 \pm 5.5$ & $99.0 \pm 5.8$ \\
\hline $\mathrm{FEV}_{1.0}$ & $102.7 \pm 13.0$ & $107.4 \pm 11.3$ & $102.3 \pm 13.3$ & $102.4 \pm 13.2$ \\
\hline PEF & $96.8 \pm 17.7$ & $105.9 \pm 15.8^{\mathrm{a}, \mathrm{b}, \mathrm{c}}$ & $93.3 \pm 19.2$ & $94.8 \pm 19.9$ \\
\hline $\mathrm{MEF}_{75}$ & $100.0 \pm 19.9$ & $109.3 \pm 20.7 \mathrm{a}, \mathrm{b}, \mathrm{c}$ & $95.7 \pm 20.9$ & $99.2 \pm 26.2$ \\
\hline $\mathrm{MEF}_{50}$ & $96.0 \pm 27.6$ & $104.9 \pm 32.9 \mathrm{c}$ & $102.0 \pm 27.6^{\mathrm{d}}$ & $95.2 \pm 24.8$ \\
\hline $\mathrm{MEF}_{25}$ & $92.9 \pm 39.1$ & $105.4 \pm 39.8$ & $99.5 \pm 35.5$ & $99.0 \pm 35.8$ \\
\hline $\mathbf{M E F}_{50} / \mathbf{M E F}_{25}$ & $107.0 \pm 26.1$ & $102.1 \pm 28.1$ & $104.1 \pm 24.1^{d}$ & $96.8 \pm 20.6$ \\
\hline
\end{tabular}

Duration of involving $\mathrm{H}_{2} \mathrm{~S}$ exposure was $11.7 \pm 5.9$ years in Group 1 and $12.6 \pm 6.8$ years in Group 2. Of the $115 \mathrm{H}_{2} \mathrm{~S}$ exposed workers, three were said to have so called "gaseous eyes" or chemical keratoconjunctivitis due to $\mathrm{H}_{2} \mathrm{~S} 10$ years earlier. The PEFR and $\mathrm{MEF}_{75}$ were significantly higher in the non-smoking $\mathrm{H}_{2} \mathrm{~S}$-exposed group than in the other three groups. When the non-smoking $\mathrm{H}_{2} \mathrm{~S}$ exposed group and the non-smoking non-exposed group were compared, the FVC and $\mathrm{MEF}_{50}$ were significantly higher in the former group. Thus, no adverse effects of longterm viscose exposure on pulmonary function were noted in these results.

In the cross-sectional prevalence study on respiratory symptoms for detecting the long-term effects of viscose exposure, 62 workers in three plants were interviewed by one of the authors using the same standard questionnaire one month after the survey by the self-administered method. Table 6 shows the comparison of the two methods with regard the responses to some principal symptom items. Although self-administered response rates generally tended to be higher than those obtained by interviews, no significant difference was found in this case by the chi square goodness of fit test.

Using the logistic regression model as stated in the chapter of subjects and methods, ${ }^{17,18)}$ multifactorial associations of the respiratory symptoms and the environmental and social variables were obtained (Table 7). The means and standard deviations of the variables were $39.6 \pm 9.9$ for age, $1.46 \pm 0.79$ for location of plants, $1.08 \pm 0.55$ for history of education, $0.83 \pm 0.43$ for marital status, $0.54 \pm 0.44$ for work category, $0.08 \pm 0.27$ for type of shift, $0.65 \pm 0.83$ for duration of viscose exposure and $1.41 \pm 0.83$ for smoking habits. The regres- 
Table 6. Response in self-administered and interview methods $(n=62)$

\begin{tabular}{clrrr}
\hline \multirow{2}{*}{ No. $^{\alpha}$} & \multicolumn{1}{c}{ Symptoms } & \multicolumn{2}{c}{ Number (\%) of questionnaire responses } \\
\cline { 3 - 5 } & & $\begin{array}{c}\text { Self-administered } \\
\text { positive }\end{array}$ & $\begin{array}{c}\text { Interview } \\
\text { positive }\end{array}$ & $\begin{array}{c}\text { positive } \\
\text { Both }\end{array}$ \\
\hline 1 & Cough in morning & $12(19.4)$ & $10(16.1)$ & 9 \\
6 & Phlegm in morning & $15(24.2)$ & $14(22.6)$ & 12 \\
$12 \mathrm{a}$ & Coughand phlegm & $4(6.5)$ & $0(0)$ & 0 \\
$14 \mathrm{a}$ & Breathlessness & $10(16.1)$ & $9(14.5)$ & 9 \\
$15 \mathrm{a}$ & Wheezing & $13(21.0)$ & $11(17.7)$ & 10 \\
& Experience of lung related diseases & $4(6.5)$ & $3(4.8)$ & 3 \\
\hline
\end{tabular}

$\alpha$ : Question code number of BMRC questionnaire (1976).

Table 7. Logistic regression analysis ${ }^{\alpha}$ of prevalence of pulmonary symptoms and independent variables $(\mathbf{n}=5347,18$ plants).

\begin{tabular}{|c|c|c|c|c|c|c|c|c|c|}
\hline \multirow[b]{2}{*}{ No. ${ }^{\beta}$} & \multirow[b]{2}{*}{ Symptoms } & \multicolumn{8}{|c|}{ Variables $^{\gamma}$} \\
\hline & & Age & $\begin{array}{l}\text { Loca- } \\
\text { tion }\end{array}$ & $\begin{array}{l}\text { Educa- } \\
\text { tion }\end{array}$ & $\begin{array}{l}\text { Marital } \\
\text { status }\end{array}$ & $\begin{array}{l}\text { Work } \\
\text { category }\end{array}$ & Shift & $\begin{array}{l}\text { Viscose } \\
\text { exposure }\end{array}$ & $\begin{array}{l}\text { Smoking } \\
\text { habits }\end{array}$ \\
\hline 1 & Cough in morning & $.142^{*}$ & .291 & .001 & .355 & -.074 & -.143 & -.008 & $.549 * *$ \\
\hline 6 & Phlegm in morning & .015 & .297 & $.149 *$ & .033 & -.312 & -.119 & .186 & $.503^{* *}$ \\
\hline $12 \mathrm{a}$ & Cough \& phlegm & .022 & .216 & $.295^{*}$ & .386 & -.418 & -.185 & -.127 & .102 \\
\hline $14 a$ & Breathlessness & $.146^{* *}$ & $k \quad .045$ & -.062 & .288 & .049 & -.191 & .016 & $.169 * *$ \\
\hline \multirow[t]{2}{*}{$15 \mathrm{a}$} & Wheezing & -.134 & -.110 & $.188^{*}$ & .045 & -.338 & -.239 & -0.40 & $.173^{* *}$ \\
\hline & $\begin{array}{l}\text { Experience of lung } \\
\text { related diseases }\end{array}$ & .306 & -.078 & .188 & -.148 & -.055 & -.114 & -.176 & .063 \\
\hline
\end{tabular}

*: Statistically significant coefficent at 0.05 level.

**: Statistically significant coefficient at 0.01 level.

$\alpha: \quad \log$ odds $(\lambda \mathrm{i})=\mathbf{A}_{0}+{ }_{1} \cdot$ Age $+\mathbf{A}_{2} \cdot$ Locatiaon $+\mathbf{A}_{3} \cdot$ Education $+\mathbf{A}_{4} \cdot$ Marital status + $A_{5} \cdot$ Work category $+A_{6} \cdot$ Shift $+A_{7} \cdot$ Viscose exposure $+A_{8} \cdot$ Smoking habits.

$\beta$ : Question code number of BMRC questionnaire (1976).

$\gamma$ : Age (years); Location (Southern=1 Inland sea =2, Central=3, Northern=4); Education (Junior high $s c h o o l=1$, Senior high school=2, College or higher=3); Marital status (Not married =0, Married=1); Work category (Office worker =0, Others =1); Shift (Daytime worker $=0$, Shift worker $=1$ ); Viscose exposure (No history of viscose work $=0,1-9$ years =1, 10-19 years=2, More than 20 years=3); Smoking $($ Never smoked $=0$, Former smoker $=1$, Current smoker $=2$ ).

sion coefficients for all the variables are also listed in the same Table. Major significant associations existed for factors related to smoking habits and history of education, but there were no significant associations between the presence of symptoms and the duration of viscose exposure.

Table 8 shows the prevalence rates of respiratory symptoms by smoking category for he 40-to-49 age group. The results clearly indicated that the rate increased as the amount of smoking rose. The same relationship was found in the other age groups as well. The difference of the prevalence rates between workers who had been exposed for more than 10 years and the non-exposed referents was also 
Table 8. Prevalence rates of pulmonary symptoms by smoking category, 40-49 years

\begin{tabular}{clccc}
\hline No. $^{\alpha}$ & \multicolumn{1}{c}{ Symptoms } & $\begin{array}{c}\text { Non-smokers } \\
(\mathrm{n}=509)\end{array}$ & $\begin{array}{c}\text { Light smokers } \\
{ }^{\alpha} \\
(\mathrm{n}=635)\end{array}$ & $\begin{array}{c}\text { Medium \& heavy }{ }^{\gamma} \\
\text { smokers } \\
(\mathrm{n}=1029)\end{array}$ \\
\hline 1 & Congh in morning & 4.6 & $7.3^{\mathrm{c}}$ & $11.8^{\mathrm{aa}, \mathrm{b}}$ \\
6 & Phlegm in morning & 8.4 & $12.7^{\mathrm{c}}$ & $18.5^{\mathrm{aa}, \mathrm{bb}}$ \\
$12 \mathrm{a}$ & Cough \& Phlegm & 1.6 & 2.8 & $3.6^{\mathrm{a}}$ \\
$14 \mathrm{a}$ & Breathlessness & 11.3 & 15.0 & $15.8^{\mathrm{a}}$ \\
$15 \mathrm{a}$ & Wheezing & 9.9 & 13.6 & $17.2^{\mathrm{aa}}$ \\
& $\begin{array}{l}\text { Experience of lung } \\
\text { related diseases }\end{array}$ & 3.4 & 3.6 & 3.7 \\
\hline
\end{tabular}

$\alpha$ : Question code number of BMRC questionnaire (1976).

$\beta$ : Former smokers $(n=23)$, and smokers who consume less than 15 oigarettes per day.

$r$ : Smokers who consume 15 or more cigarettes per day.

$\left.\begin{array}{rl}\text { a: } & p<0.05 \\ \text { aa: } & p<0.01\end{array}\right\}$ Non-smoker vs medium \& heavy.

$\left.\begin{array}{rl}\mathrm{b}: & \mathrm{p}<0.05 \\ \mathrm{bb}: & \mathrm{p}<0.01\end{array}\right\}$ Light smoker vs medium \& heavy.

found to be insignificant in each smoking category.

The results obtained from the two sets of studies, diurnal exposure and crosssectional prevalence of respiratory symptoms, may well lead to the conclusion that viscose exposure, especially to $\mathrm{H}_{2} \mathrm{~S}$, would not cause adverse pulmonary effects in the course of routine long-term occupational exposure under current work conditions.

\section{Discussion AND Conclusion}

Repeated short-term or instant peak exposure to a toxic substance with reversible physiological effects may lead to a subsequent chronic irreversible impairment, if each stimulus is effective enough to induce a biological change. The outcome may be recognized by a cross-sectional prevalence study in an occupational, exposure-referent population. Based on this hypothesis, two types of epidemiological designs were adopted simultaneously in the present study, a one-day effect of exposure study in a selected small number of rayon plant workers and cross-sectional prevalence rates of respiratory symptoms in a large number of rayon workers throughout the industry. It has been reported (Holland et al.; Leader et al. $)^{19,20)}$ that, in London, recurrent episodes of respiratory tract distress at young ages have led to subsequent chronic ventilatory impairment or illness.

In the diurnal exposure study, matched pair sampling and the regression procedure was adopted to remove confounding bias. Those methods have been rcommended in observational epidemiological studies (Rubin). ${ }^{21)}$ The results indicated there is no exposure-response gradient between the personal occupational exposure level (OEL) and the individual degree of diurnal effects on pulmonary 
function. These negative results might be due to insufficient environmental stimulation or weak sensitivity of physiological parameters capable of detecting the effects, despite pertinent matching procedures for age, sex, height and cigarette smoking habits, and careful performance of measurements of pulmonary function designed for before and after occupational exposure, as well as painstaking application of the $\mathrm{H}_{2} \mathrm{~S}$ personal dosimeter to the pairs. The ventilatory capacity obtained from forced expiratory flow-volume curves has been determined to be a sensitive indicator for detecting the effects of environmental pollution in epidemiological studies (Stanescu). ${ }^{22}$ To avoid technical error, every pulmonary measurement was undertaken by a single trained lung physician with his single epidemiologically approved instrument.

When any significant difference in the function was detected between the pair, it might reasonably be considered that the result was induced by viscose vapor, that is, at least three common chemical components existing in the environment, $\mathrm{H}_{2} \mathrm{~S}, \mathrm{CS}_{2}$ and $\mathrm{H}_{2} \mathrm{SO}_{4}$. The annual average concentration of co-existing gaseous confounders in the spinning rooms of 18 plants was reported from the internal information of the Japan Chemical Fiber and Textile Association as follows; $1.3 \mathrm{ppm}$ for $\mathrm{H}_{2} \mathrm{~S}, 4.0 \mathrm{ppm}$ for $\mathrm{CS}_{2}$ and less than $0.1 \mathrm{mg} / \mathrm{m}^{3}$ for $\mathrm{H}_{2} \mathrm{SO}_{4}$. The respective occupational threshold limit values are $10 \mathrm{ppm}$ for $\mathrm{H}_{2} \mathrm{~S}$ and $\mathrm{CS}_{2}$ and $1 \mathrm{mg} / \mathrm{m}^{3}$ for $\mathrm{H}_{2} \mathrm{SO}_{4}(\mathrm{JAIH}){ }^{23)}$ Adaptation to $\mathrm{H}_{2} \mathrm{~S}$, especiaily to its odor, should be taken into consideration, although $\mathrm{Poda}^{24)}$ stated that no sensitivity change has been observed after over-exposure to $\mathrm{H}_{2} \mathrm{~S}$. The association between odor of $\mathrm{H}_{2} \mathrm{~S}$ and pulmonary function, though not involved in this study, is a matter to be further investigated.

It must be noted that, in percentage-predicted pulmonary functions of viscose exposed workers by smoking category (Table 5), non-smoking viscose workers appeared to have higher values in FVC, PEFR and $\mathrm{MEF}_{75}$ than non-smoking referents, and PEFR and $\mathrm{MEF}_{75}$ were also higher than in other groups. These peculiar findings, that is the favorable values in non-smoking viscose-exposed workers, may be interpreted as not only indicating no adverse effects of viscose exposure, but may also be a result of "health promotion effects" that may be due to more intensive occupational health care for the exposed workers than the non-exposed or there may be "healthy worker selection effects" (Vinni et al.), ${ }^{25)}$ that is relatively healhy workers were selected to do at the preplacement.

In the comparison of the two questionnaire methods, self-administered and interview, slightly higher prevalence rates of respiratory symptoms were obtained in the former. It has been reported that self-completion surveys usually yields significantly greater numbers of positive responses (Mittman et al.). ${ }^{26)}$ The difference of the prevalence rates in the present study was so small (Table 6) that both methods could be considered acceptable.

It has been well documented that prevalence rates of respiratory symptoms are always higher in smokers than in non-smokers (Brinkman et al.; Hrubec et 
al.). ${ }^{27,28)}$ In our results, significant associations were found between positive respiratory response and such variates as smoking habits and education, but not duration of $\mathrm{H}_{2} \mathrm{~S}$ exposure (Table 7). This might confirm that there were no long-term chronic effects of $\mathrm{H}_{2} \mathrm{~S}$ exposure on respiratory symptoms and the prevalence of respiratory symptoms increased as cigarette consumption increased (Tables 7 and 8 ). The significance of the positive relationship between the educational levels and the prevalence of respiratory symptoms might be associated with "urban-rural factors" (Holland et al.). ${ }^{29)}$

Supplemented with the one-day exposure study on 30 matched pair workers, the negative results of the cross-sectional prevalence study on respiratory symptoms in 5347 viscose rayon workers in this country may lead to the conclusion that $\mathrm{H}_{2} \mathrm{~S}$ exposure, at least $3 \mathrm{ppm}$ of occupational exposure level (OEL) or $1.3 \mathrm{ppm}$ of annual mean concentration in the working room, causes neither acute nor chronic appreciable adverse effects on pulmonary function and respiratory symptoms.

This paper was presented at the Second International Symposium on Epidemiology in Occupational Health in August 1982 in Montreal, Canada.

\section{REFERENCES}

1) Kubota, J. (1967). Toxicology of Carbon Disulfide, p. 192. Excerpta Medica Foundation, Amsterdam.

2) Hernberg, S., Partanen, T., Nordman, C.H. and Sumari, P. (1970). Coronary heart disease among workers exposed to carbon disulfide, Br. J. Ind. Med., 27, 313.

3) Hänninen, H. (1971). Psychological picture of manifest and latent carbon disulfide poisoning, Br. J. Ind. Med., 28, 374.

4) Fajen, J., Albright, B. and Leffingwell, S.S. (1981). A cross-sectional medical and industrial hygine survey of workers exposed to carbon disulfide, Scand. J. Work. Environ. Health., 7, Suppl. 4, 20.

5) Nyman, H.T. (1951). Hydrogen sulfide eye-inflammation, Treatment with cortisone, Ind. Med. Surg., 23, 161.

6) Milby, T.H. (1962). Hydrogen sulfide in toxication; review of the literature and report of unusual accident resulting in two cases on nonfatal poisoning, J. Occup. Med. 4, 431.

7) Simson, R.E. and Simpson, G.R. (1971). Fatal hydrogen sulfide poisoning associated with industrial waste exposure, Am. Rev. Pespir. Dis., 119, 831.

8) Smith, R.P. and Gosselin, R.E. (1979). Hydrogen sulfide poisoning, J. Occup. Med., 21, 93.

9) Kemper, F.D. (1966). A near-fatal case of hydrogen sulfide poisoning, Can. Med. Assoc. J., 94, 1130.

10) Burnett, W.W., King, E.G., Grace, M. and Hall, W.F. (1977). Hydrogen sulfide poisoning: review of 5 years' experience, Can. Med. Assoc. J., 117, 1277.

11) National Institute for Occupational Safety and Health Administration (1978). Occupational Health Guideline for Hydrogen Sulfide, p. 1. U.S. Government Printing Office, Washington, D.C.

12) Nakaza, M., Toyama, T. and Omae, K. (1980). A personal diffusion sampler for 
evaluating time weighted exposure to gaseous hydrogen sulfide, Jap. J. Ind. Health, 22, 372.

13) American Public Health Association (1975). Methods of Air Sampling and Analysis, p. 426. American Public Health Association, Washington, D.C.

14) McKee, R.W. (1941). A quantitative microchemical colorimetric determination of carbon disulfide in air, water and biological fluids, J. Ind. Hyg., 23, 151.

15) Sorensen, J.B., Morris, A.H., Crapo, R.O. and Garaner, RM. (1980). Selection of the best spirometric values for interpretation, Am. Rev. Respir. Dis, 122, 802.

16) Sakurai, H., Omae, K., Toyama, T., Higashi, T., Nakadate, T. (1982). Cross-sectional study of pulmonary functions in cadmium alloy workers, Scand. J. Work. Environ. Health, 8, Suppl. 1, 122.

17) Cox, D.R. (1974). Analysis of Binary Data, p. 14. Methuen, London.

18) Lemeshow, S. and Hosmer, D.W. (1982). A review of goodness of fit statistics for use in development of logistic regression model, Am. J. Epidemioı., 115, 92.

19) Holland, W.W., Halil, T., Bennett, A.E. and Elliot, A. (1969). Indications for measures to be taken in childhood to provent chronic respiratory disease, Milbank Mem. Fund Ouart., 47, pt. 2, 215.

20) Leeder, S.R., Cockhill, R.T., Wysocki, M.J. and Holland, W.W. (1976). Influence of family factors on the incidence of lower respiratory illness during the first year of life, Brit. J. Prev. Soc. Med. 30, 219.

21) Rubin, D.B. (1973). The use of matched sampling and regression adjustment to remove bias in observaational studies, Biometrics, 29, 185.

22) Stănescu, D.C. (1976). Early detection of chronic bronchitis and pulmonary emphysema, p. 25. Stenfert Krosse, Leiden.

23) Japan Association of Industrial Health (1982). Permissible exposure levels in work air for 1982, Jpn. J. Ind. Health, 24, 528.

24) Poda, G.A. (1966). Hydrogen sulfide can be handled safely, Arch. Environ. Health, 12, 795.

25) Vinni, K. and Hakama, M. (1980). Healthy worker effect in total finnish population, Br. J. Ind. Med. 37, 180.

26) Mittman, C., Barbela, T., McCaw, D. and Pedersen, E. (1979). The respiratory disease questionnaire: Use of self-administered version, Arch. Environ. Helath, 33, 151.

27) Brinkman, G.L. and Coates, O.E. (1962). The prevalence of chronic bronchitis in an industrial population, Am. Rev. Respir. Dis., 86, 47.

28) Hrubec, Z., Cederlof, R., Friberg, L., Horton, R. and Ozolins, G. (1973). Respiratory symptoms in twins: Effects of residence associated air pollution, tabacco and alcohol use, and other factors, Arch. Environ. Health, 27, 189.

29) Holland W.W. and Reid, D.D. (1965). The urban factor in chronic bronchitis, Lancet, 1. 445 . 